\title{
Reassessing Prospects for the Open Access Movement
}

\section{Charles A. Schwartz}

\begin{abstract}
Open access may well be a turning point for the scholarly communication system, but not on the basis claimed by its advocates. As opposed to the claim that open access means a less costly system, in reality it entails redundant expenditures and inflationary pressures. The true significance of open access, involving processes of institutional development of the system, has not entered into the public debate. Such processes are chiefly twofold: the adjustment of the open-access movement to the different needs and cultures of the various stakeholder groups, and the advent of a more complex system architecture that facilitates research productivity and scholarly innovation.
\end{abstract}

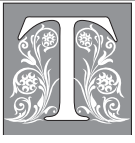

he scholarly communication crisis is entering its fourth decade. Since the early 1970s, it has expanded in scope, scale, and complexity as the scholarly system itself has developed. The issues now range from the declining market for the traditional monograph to the emerging political economy of the networked environment but center on journal price inflation in the sciences. Given the diversity of the various stakeholder groups (university administrators, research libraries, learned societies, nonprofit presses, publishing conglomerates, and the scholars themselves spread over hundreds of disciplines), it is little wonder that no one in thirty years has devised a generally viable reform proposal.

Open access has the prospect of becoming a turning point in this state of affairs, but not on the basis claimed by its advocates. Indeed, the conventional arguments of open access are doubtful, whereas its real significance, involving processes of institutional development of the scholarly system, has not entered into the public debate. The basic problem of institutional development is the lag of societal (political, economic, social, and so on) arrangements behind technological change. The open-access movement signifies such a lag. It is the rough outline of the system's future by virtue of the technological progress it represents. What remains to be seen are the ways the movement adjusts to the differing business interests, publishing norms, and professional cultures of the stakeholder groups. In systems analysis, that process will reflect the diversity advantage of each group's freedom to manage constant change and increasing environmental complexity. ${ }^{1}$

The discussion falls into six main parts. The first part outlines the open-access movement's generic business model.

Charles A. Schwartz is Associate Director of Collection Management at Florida International University; e-mail: schwartc@fiu.edu. This article benefited from several reviewers: John Budd, Gail Clement, Blaise Cronin, Raym Crow, Marshall Deason, John Ingram, Don Riggs, Tom Sanville, Peter Suber, Laura Walters, and Stephen Wiberley. 
Part two assesses that model in light of journal editors' commentaries. Part three describes the economic prospects of open access for the system as a whole. The next two parts take up the institutional development of the system in terms of increased architectural complexity and, with reference to the journal conglomerates' Big Deal model, the tipping point theory of innovation diffusion. The final part provides a summary with a few areas for future research.

\section{Open Access in Its Pure Form}

Open access is not a centralized entity but, rather, a cluster of loosely coordinated publishing ventures (e.g., the Public Library of Science and its affiliates in biology and in medicine) and advocacy groups (e.g., Creative Commons, SPARC, Public Knowledge). It aims to make freely accessible in online journals scientific and scholarly research, particularly that done with public funding. The movement's strength is the technology that enables the sharing of digital resources by the global scientific community. Its passion draws on the universal assent that the scholarly communication system is neither technologically adequate for the research and education enterprise, nor financially sustainable for research libraries. The movement's key difficulty is on the financial side. As opposed to its claim that open access would mean a less costly system, in reality, it entails redundant expenditures and inflationary pressures.

The generic business model designed by advocacy groups has two features: copyright stays with authors and institutions that consent to open access, and publishing costs shift from subscriptions to a set of abstractly plausible (or hypothetical) funding sources. For many reasons - political and practical, but primarily economic, to preserve the financial basis of the print regime-the movement does not challenge the for-profit establishment, preferring to label itself "constructive, not destructive." ${ }^{2}$

\section{Complexities and Realties of Business Models}

The copyright feature of this model is hardly controversial; no change in law is called for and most publishers agree to limited forms of open access. The disputes concern the funding sources and access conditions for articles to be freely distributed as public goods. Where the movement proposes an array of speculative sources, publishers perceive a paucity of realistic options. In their view, of all the revenue-generating options listed in the movement's literature-author submission and publication fees, printsubscription profits, advertising, higher society membership dues, university fee agreements, grants, and value-added search services-only the first two are readily plausible as long-term strategies. The others would not be reliable enough for publishers to weather fluctuations in the economy. ${ }^{3}$

Moreover, the principal funding sources, author fees and print profits, are likely to be volatile market forces. Authors who lack grant support would reasonably take into account the size of fees in deciding where to submit their work. Publishers would attract authors by lowering fees, thereby raising library prices. To preserve library subscription revenues, publishers would withhold articles from open access for a year or so, already the prevailing practice. To attract more manuscripts, publishers would broaden the topical scope-and physical size- of journals, another inflationary pressure on the print side.

Smaller libraries would tend to cancel print subscriptions to the price-inflated open-access journals, thereby driving up prices for larger libraries that must maintain subscriptions for the sake of researchers' productivity. If there is anything learned from the thirty years' crisis, it is this very pattern of escalating prices for captive-market libraries in the wake of successive rounds of nationwide cancellations. 
The financial situation of libraries also would deteriorate with the open-access proposal that universities cover their faculties' author fees. It is difficult to see how that scheme would be feasible for any but the richest institutions unless funding was diverted from the library's budget. Indeed, some open-access advocates would have libraries cut their collections in order to provide financial assistance to the movement. The prospect in either case would be for local budget crises to aggravate the nationwide one. ${ }^{4}$

\section{Economic Prospects for Open Access}

We have a conundrum. The open-access movement cannot be expected to address the whole series of factors underlying prolongation of inflation since the 1970s. Any such strategy to explore new institutional arrangements needs to focus on attainable goals - in this case, by creating an extraordinary online system without attending to a host of collateral issues. Yet, scientific and scholarly information as a public good is bound to lead to a more costly scholarly communication system on the whole. It also is likely to turn authors in disciplines for which journal charges are not the norm into classic utility maximizers.

The tight relationship between openaccess publishing and print-subscription revenue streams has been overlooked or ignored in the debate. The claim that open access would be less expensive is simply based on a few factors that pertain to online publishing as a self-contained activity (e.g., negligible marginal-production costs, the absence of mailing charges).

The actual structuring of open-access operations will be in the hands of those publishers who have the right entrepreneurial stuff. Each discipline (or community of practice) will have to devise business models that are culturally and professionally appropriate, as well as financially sustainable. Some standardization may evolve from the diffusion of best practices.
Analogous activities have been under way in other areas of the scholarly communication system. To recognize them may avoid the situation where, to recall a verse of T. S. Eliot, "we had the experience but missed the meaning." Digital library operations, like open-access models, are not based on fixed concepts but, rather, on processes that are under constant transformation. The political economy of digital libraries as community spaces in the networked environment is an unsettled area. There is no universal governance or cost-recovery scheme. Although many of these spaces resemble information commons in which resources are public goods, there are constant pressures for their resources to take the character of market-driven commodities. In such respects, the challenges of economic sustainability for digital libraries and for open-access journals are analogous.

\section{Open Access and Institutional Development: Architectural Complexity}

On an altogether different level, open access will restructure the scholarly communication system. This involves the system's architectural complexity. Scholarly communication is a loosely coupled system. Patterns of influence and interaction, certainly among the hundreds of disciplines, are somewhat responsive, but predominately erratic: circumscribed, dampened, mutated, infrequent, weak, or delayed. (For a university, this is known as "organized anarchy.")

Loosely coupling is not incidental but, instead, provides for essential functions, such as flexibility, innovation, and cost containment on local levels. Grand reform proposals - to the extent that they are intended to create a more "rational" institutional order - are bound to impair the chief strength of loose coupling: its capacity to manage constant change and increasing environmental complexity.

As a rule, change occurs in the scholarly communication system within groups, hardly across them, resulting in conspicu- 
ous communication gaps and cultural lags among the various disciplines and fields. Such disconnectedness has been depicted in well-known images: C. P. Snow's "two cultures," Gabriel Almond's "separate tables," Nobel Laureate Herbert Simon's "empty universe," in which learning environments have "millions of variables that in principle could affect each other but most of the time don't." ${ }^{5}$

System complexity is based on the opposite characteristics of Weblike forms of communication and interdependence. In those respects, the scholarly communication system has a rather rudimentary architecture. Open access is designed to develop the system's capacity for cross-disciplinary search and retrieval, which will enhance research productivity and scholarly innovation. This technologically robust prospect may be a more cogent rationale for the open-access movement than the financially pale social principle that scholarly articles ought to be a public good.

The premises of this prospect (which has not caught the attention of researchers generally) are certain "laws of the network." Metcalf's Law: the value of the network grows as the square of the number of users. Kao's Law: the power of creativity rises exponentially with the diversity and divergence of those connected to the network. ${ }^{6}$ Along such lines, open access will reform to some extent the system's characteristic disconnectedness among disciplines. Although this capacity for crossdisciplinarity may be difficult to gauge in a comprehensive way, it should become evident in one's own online work. After all, from the perspective of innovation diffusion models for loosely coupled systems, such as tipping point theory, the hallmark of success is the realization that things are connected in cool ways that one had not expected.

\section{Open Access and Institutional Development: Tipping Point Theory and the Big Deal}

Prospects for the scholarly communication crisis do not ride on social principles about scholarly information as a public good. The key sets of factors are economic and institutional, exemplified by three general types of strategies to reform a loosely coupled system.

The radical type of strategy is to explore new institutional arrangements: the open-access movement. The conservative type is to exploit or refine existing arrangements: the Big Deal (described below). The intermediate strategy, the one proposed here, is for the established publishers to steer the reform movement with open-access business models that take realistic account of their distinct business interests and professional cultures. Such a strategy reflects the diversity advantage in loosely coupled systems of each stakeholder group's freedom to manage constant change and increasing environmental complexity on its own.

The conservative type of strategy, to exploit or refine existing arrangements, came to the fore in the late 1990s with the Big Deal, which is a package of most or all of a publisher's online journals, usually for consortia. For the publisher, this model has two advantages: it secures revenue streams, and it expands access to its list of journals at low marginalproduction costs. Such access may lead to higher citation rankings for some journals, leveraging the package's overall market value.

For librarians, the Big Deal has led to profound ambivalence. ${ }^{7}$ Although it expands collections and makes for more predictable budgets, and thus some peace of mind, this strategy has what economists call moral hazards. Price increases, though more restrained than in the past, are inescapable. Bundling of essential and nonessential titles knocks out whatever remains of market controls, as well as the expert role of library collections staff. On the national scale, journal collections become more homogenized, particularly as smaller publishers are crowded out (like university press monographs) of library budgets. Overall, the Big Deal may be a "competency trap" in which an organization gets locked into arrangements that 
alleviate certain pressures but may be ill suited in the long run.

The tipping point model of the diffusion of open-access publishing cropped up in 2003 when a European financial group issued an "underperform" stock rating for the largest journal conglomerate (Elsevier) on the basis of the impending threat of open access. The report's indeterminate time frame (the next ten years) is premised on one of the possible patterns of change in a loosely coupled system: delayed, but eventually swift, progression (like the "bandwagon effect"). ${ }^{8}$

Tipping point theory for the open-access movement should be scaled down to the gradual tempo of deliberate business modeling by publisher or field. Rather than the usual portrayal of sudden and dramatic transformation, we should expect a series of bounded tipping points for the various disciplines or communities of practice. The diffusion of business models in the system will resemble the way that organizations share best management practices: adapting broad ideas to local circumstances.

As for what might be called the Grand Tipping Point scenario, in which the open-access movement overtakes the Big Deal, we are not likely to witness the fall of oligopoly but, rather, an extension of the same accommodations to preserve print revenues. What is likely to dissolve is the relative simplicity of the present Big Deal, leaving academic libraries with a strikingly more complex environment for cost-effective serials management, given the need to take into account openaccess and print formats for hundreds of journals.

\section{Conclusions}

The subtleties and complications of open access for the scholarly communication system will take years to emerge. Some issues are distant and indistinct, such as creation of a "universal online journal archive." Even for immediate issues, notably the general reaction of authors in disciplines for which journal charges are not the norm and the trend of posting abstracts rather than full-text articles in supposedly open-access journals, little is known in any systematic or empirical way. Five main considerations may lead to more coherent discussions, which have veered between intellectual drift and groupthink over the past thirty years.

First, in what appears should be an historic stage for the system, its potential for the kind of institutional development that would enable the global sharing of digital scholarly and scientific information, the most sensible steps are openaccess business models for particular disciplines or communities of practice. As it is more realistic to aim for change within components than across them in a loosely coupled system, strategies should be designed to produce fairly distinct and limited reforms for particular groups. From the standpoint of the system at large, successful models will balance local freedom (adaptability and innovation to meet the test of cultural and problem-specific appropriateness) with institutional order (best practices and economies of scale).

Second, such models will not amount to an economic revolution, given the prospect of redundant costs and prolongation of inflation for the system. Rather, they will reflect in diverse ways the essential tension between innovation and tradition. The future of open-access business models has at least two traditional, but functional, conditions. One is for the diversity advantage of each community to manage constant change and environmental complexity on its own. The other condition is the nearly inescapable coupling in most fields of open-access publishing schedules to print-subscription revenue streams, which entail online delays and inflationary pressures.

The movement's claim that it is "constructive, not destructive" reflects this tension between innovation (technological prospects) and tradition (print revenues). Its claim that "any concerted effort by governments to make the results of pub- 
licly funded research freely available will ultimately have profound benefits for the general public, for scientists, and for science itself" may be true on one level but does not take into account whether that effort will lead to a system that is economically sustainable for academic libraries.

Third, the kind of tipping point theory of interest here (based on innovation diffusion of business models) is wholly distinct from the decades' old notion of a tipping point that would come from a political rebellion of scholars against the publishing conglomerates. ${ }^{9}$ In our view, which was also the theme of a recent Association of Research Libraries' conference, scholars are, by and large, research-productivity utility maximizers who have little or no interest in participating in schemes for an acrossthe-board restructuring of the scholarly communication system. ${ }^{10}$ Their concerns are predominately discipline centric. The systems analysis presented here may rekindle the thirty years' ideological war, though some movement advocates now make the astonishing claim that further research and analysis is retrograde: "It is time to move beyond rehashing tired arguments about whether open access poses a threat to publishers, professional societies, or research budgets. We should begin to discuss how best to use what open access gives us: the unfettered availability of scholarly literature."11

Fourth, the architectural revolution in the system's capacity for cross-disciplinarity will be somewhat muffled by the financially induced delays in full articles coming online. Such delays are offset by the posting of abstracts. That serves researchers' productivity but underscores the general dependence of the open-access movement on the university library (in the same way that the notion of the Google revolution leads back to local library holdings). The overall prospect is mixed: a partially open-access system having a more complex architecture that promotes research productivity and scholarly innovation.

Finally, any reform proposal should take into account the nearly defiant complexity and scale of scholarly communication. Faced with hundreds of disciplines that have their own logics and an inherent bent toward self-determination, we have reason to be skeptical of grand schemes and generic models. The open-access movement will progress the way other innovations do in a loosely coupled system, on the strength of weak ties: the diffusion and eventual aggregation of professional communities' best practices.

\section{Notes}

1. For a general description of institutional development of academic libraries, see Charles A. Schwartz, "Restructuring Academic Libraries: Adjusting to Technological Change," in Restructuring Academic Libraries: Organizational Development in the Wake of Technological Change, ed. Charles A. Schwartz. Publications in Librarianship no. 49 (Chicago: Association of College \& Research Libraries, 1997), 1-30, available online at ALA's ACRL PIL Web site.

2. For descriptions of generic open-access business models framed by the movement's advocates, see "Budapest Open Access Initiative, Frequently Asked Questions," available online at http://www.earlham.edu/ peters/fos/boaifaq.htm; Open Society Institute, "Guide to Business Planning for Launching a New Open Access Journal," edition 2 (July 2003), available online at http://www.soros.org/openaccess/oajguides/oaj_supplement_0703.pdf; Public Library of Science, "Open Access," available online at http://www.plos.org/about/openaccess.html; John M. Unsworth, "The Next Wave: Liberation Technology," Chronicle Review (Chronicle of Higher Education) 50, no. 21 (Jan. 30, 2004): B16; Thomas J. Walker, "Two Societies Show How to Profit by Providing Free Access," Learned Publishing 15 (2002): 279-84; Wellcome Trust, "Costs and Business Models in Scientific Research Publishing," available online at http://www.wellcome.ac.uk/doc_WTD003185. html.

3. For more cautious and realistic accounts of the complexity of open-access business models, see Rick Anderson, "Open Access in the Real World: Confronting Economic and Legal Reality," College $\mathcal{E}$ Research Library News 65, no. 4 (Apr. 2004): 206-8, available online at http://www.ala. 
org/ala/acrl/acrlpubs/crlnews/backissues2004/april04/openaccess.htm; B. C. Björk, "Open Access to Scientific Publications: An Analysis of the Barriers to Change," Information Research 9, paper 170 (2004), available online at http://informationr.net/ir/9-2/paper170.html; Michael Clarke, "Open Sesame? Increasing Access to Medical Literature," Pediatrics 114 (July 2004): 265-68, available online at http://pediatrics.aappublications.org/cgi/content/full/114/1/265 ; Cathy N. Davidson, "Understanding the Economic Burden of Scholarly Publishing," Chronicle of Higher Education 50, no. 6 (Oct. 3, 2003): B7; Editorial, "An Open Letter to the Members of ASH: Your Membership Dues, Blood, and Open Access to the Scientific Literature," available online at http://www.hematology.org/government/policy/open_access.cfm; Editorial, "Open Access and Closed Options," EMBO Reports 5, no. 10 (2004), available online at http://www.nature.com/embor/journal/v5/n10/ pdf/7400270.pdf; Editorial, “Is a Government Archive the Best Option?" Science 291, no. 5512 (Mar. 23, 2001): 2318-19; Victoria Stagg Elliott, "Journal Free for All: The Electronic Future of Scientific Publishing," American Medical News (Apr. 19, 2004); John W. Ewing, "Open Access to Journals Won't Lower Prices," Chronicle Review (Chronicle of Higher Education) 51, no. 6 (Oct. 1, 2004): B20; John W. Ewing, "No Free Lunches: We Should Resist the Push to Rush Research Online," Chronicle Review (Chronicle of Higher Education) 48, no. 7 (Oct. 12, 2001): B14; Ron Fraser, "Open Access Publishing: Is It the Future for Scientific Journals?" SGM: Society for General Microbiology, available online at http://www.socgenmicrobiol.org.uk/pubs/SGMOpenAccess.cfm; Lila Guterman, "The Promise and Peril of 'Open Access,'" Chronicle of Higher Education 50, no. 21 (Jan. 30, 2004): A10;

"Critics and Proponents Debate NIH's Plan to Free Access to Scientific Materials," Chronicle of Higher Education 51, no. 18 (Jan. 7, 2005): A28; —_, "Scientific Societies' Publishing Arms United against Open-Access Movement," Chronicle of Higher Education 50, no. 29 (Mar. 26, 2004): A20; - "The Promise of 'Open Access' Publishing," Chronicle of Higher Education 50, no. 21 (Jan. 30, 2004): A10; _ "NIH Reportedly Is Weakening Its Plan for Free Access to Journal Articles," Chronicle of Higher Education 51, no. 21 (Jan. 19, 2005): A16; Albert Henderson, "Should Authors Pay Publishers? The Desperation of the New Paradigm," Publishing Research Quarterly 14 (winter 1998/99): 3-8; Jeffrey R. Young, "Boycott over Lack of Online Access to Journals Is a Bust," Chronicle of Higher Education 48, no. 38 (May 31, 2002): A34.

4. The notion of libraries giving up acquisition funds to scholarly societies is found in John Willinsky, "Scholarly Associations and the Economic Viability of Open Access Publishing," Journal of Digital Information 4, no. 2 (2003), available online at http://jodi.ecs.soton.ac.uk/Articles/v04/i02/ Willinsky/. The counterargument is by Mark J. McCabe and Christopher M. Snyder, "The Best Business Model for Scholarly Journals: An Economist's Perspective," News @ Nature.com, Apr. 14, 2005, available online at http://www.nature.com/nature/focus/accessdebate/28.html.

5. C. P. Snow, The Two Cultures: A Second Look (London: Cambridge Univ. Pr., 1969); Gabriel A. Almond, A Discipline Divided: Schools and Sects in Political Science (Newbury Park, Calif.: Sage, 1990); Herbert A. Simon, "How Complex Are Complex Systems?" PSA: Proceedings of the Biannual Meeting of the Philosophy of Science Association 2 (1976): 7-22.

6. On laws of the network, see Patrick O. Brown, Michael B. Eisen, and Harold E. Varmus, "Why PLoS Became a Publisher," available online at http://www.plosbiology.org/plosonline; Randall Collins, "Toward a Theory of Intellectual Change: The Social Causes of Philosophy," Science, Technology, and Human Values 14, no. 2 (spring 1989): 107-40; Gertrude Himmelfarb, "Revolution in the Library," American Scholar 66 (spring 1997): 197-204; John J. Kao, Jamming: The Art and Discipline of Business Creativity (New York: Harper Business, 1996); Geoff Mulgan, Connexity: How to Live in a Connected World (Boston: Harvard Business, School Pr.), 1997.

7. For discussions of the Big Deal, see Carl T. Bergstrom and Theodore C. Bergstrom, "The Costs and Benefits of Library Site Licenses to Academic Journals," Proceedings of the National Academy of Sciences 101, no. 3 (Jan. 20, 2004): 897-902, available online at http://www.pnas.org/; Kenneth Frazier, "The Librarians' Dilemma: Contemplating the Costs of the 'Big Deal,'" D-Lib Magazine 7, no. 3 (Mar. 2001), available online at http://www.dlib.org/dlib/march01/frazier/03frazer. html; Thomas A. Peters, “What's the Big Deal?" Journal of Academic Librarianship 27 (July 2001): 302-4; Seth Shulman, "We Need New Ways to Own and Share Knowledge," Chronicle of Higher Education 45, no. 24 (Feb. 19, 1999): A64.

8. For discussion of tipping point theory, see Mark Granovetter, "Threshold Models of Collective Behavior," American Journal of Sociology 83, no. 6 (1978): 1420-43; Robert P. Parks, "The Faustian Grip of Academic Publishing," Journal of Economic Methodology 9, no. 3 (2002): 317-35; Charles A. Schwartz, "The Strength of Weak Ties in Electronic Development of the Scholarly Communication System," College and Research Libraries 55, no. 11 (Nov. 1994): 529-40; John Willinsky and Larry Wolfson, "The Indexing of Scholarly Journals: A Tipping Point for Publishing Reform?" Journal of Electronic Publishing 7, no. 2 (Dec. 2001), available online at http://www.press. umich.edu/jep/07-02/willinsky.html.

9. The publication typically used to buttress a tipping point of scholars' rebellion, Andrew Odylzko's "The Economics of Electronic Journals," First Monday 2, no. 8 (Aug. 1997), available 
online at http://www.firstmonday.org/issues/issue2_8/odlyzko/index.html, is actually far more balanced and perspective than that. Movement advocates tend to quote only part of a famous sentence: "the central problem is that scholars have no incentive to maintain [the current expensive system]" without including another part of the sentence: "they currently also have no incentive to dismantle it."

10. Blaise Cronin, "Scholarly Communication and Epistemic Cultures, Association of Research Libraries conference, Scholarly Tribes and Tribulations: How Tradition and Technology are Driving Disciplinary Change," Oct. 17, 2003, available online at www.arl.org/scomm/disciplines/Cronin. pdf; Suzanne E. Thorin, "Global Changes in Scholarly Communication," Association of Research Libraries conference, Scholarly Tribes and Tribulations: How Tradition and Technology are Driving Disciplinary Change, Oct. 17, 2003, available online at http://www.arl.org/scomm/disciplines/Thorin. pdf.

11. Andy Gass and Helen Doyle, "The Reality of Open-Access Journal Articles," Chronicle Review (Chronicle of Higher Education) 51, no. 24 (Feb. 18, 2005): B13.

\section{Elegant Solutions for Preservation}

Call for a complete catalog

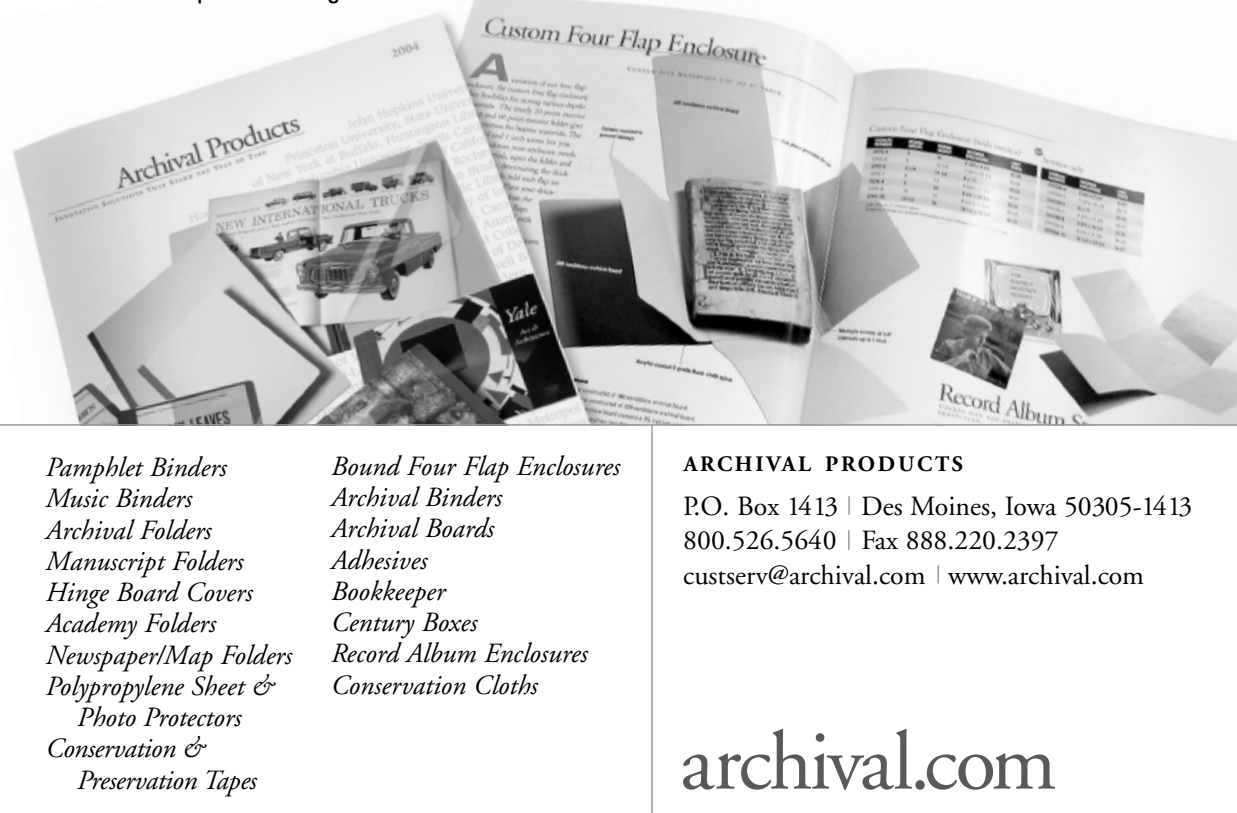

